\title{
TP53 Gene Deletion
}

National Cancer Institute

\section{Source}

National Cancer Institute. TP53 Gene Deletion. NCI Thesaurus. Code C133694.

A molecular abnormality referring to the loss of at least one copy of the TP53 gene. 